mi paciente es...

\title{
Un varón con síndrome del escroto rojo
}

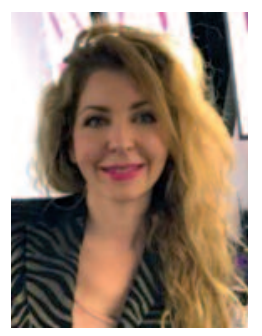

Elena González-Guerra Médico adjunto. Servicio de Dermatología. Hospital Clínico San Carlos. Madrid.

Profesora asociada de Dermatología.

Facultad de Medicina. Universidad Complutense de Madrid.

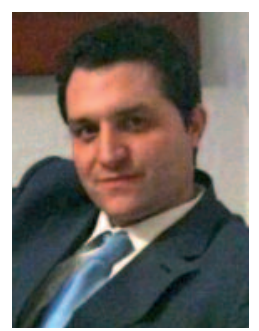

Alejandro González-Guerra Técnico especialista en Emergencias Sanitarias. SUMMA 112. Madrid.
Mi paciente es un varón de 63 años de edad, que solicita cita urgente con el dermatólogo, porque se encuentra «francamente mal», según sus palabras textuales. Refiere en su petición que requiere específicamente a «alguien que sea experto en enfermedades genitales». Supongo, al preparar la consulta, que es un paciente que sospecha tener alguna enfermedad venérea, que, aunque no es una verdadera urgencia, genera mucha ansiedad por las repercusiones emocionales y sociales, además de las físicas, que implica un diagnóstico de este tipo.

Entra en la consulta acompañado de una señora de edad madura, que me presenta como su esposa. Me sorprende, dado que, cuando se baraja el dictamen de enfermedad venérea, el paciente suele acudir solo.

Es un hombre de aspecto agradable, educado — casi cortés—, vestido formalmente con traje y corbata. Cuando inicio el turno de preguntas que conformarán la anamnesis, el paciente se explaya verbalmente, de forma rápida y ansiosa.

-Doctora, todo empezó hace unos tres meses, coincidiendo con la época veraniega y las altas temperaturas ambientales, con escozor en las ingles, que atribuí al sudor propio de la estación. Sin embargo, en muy pocos días, las molestias se extendieron al escroto, sobre todo, en la cara anterior, añadiéndose al escozor picor en crisis agudas. Las molestias eran y son muy intensas. Probé a cambiar el tipo y tejido de ropa interior; modulé el aire acondicionado bajando la temperatura de las habitaciones; me eché polvos de talco y cremas refrescantes y antisudorales. Nada ha surtido efecto. No puedo estar con otras personas, ni caminar, ni sentarme. Necesito rascarme o abanicarme constantemente, todo me molesta, siempre estoy de mal humor y sin ganas de nada. Por la noche, es todavía peor. Yo creo que tengo algo maligno. De ahí mi urgencia —me explicó.

— ¿Le ha visto algún otro médico? -le pregunté.

-Sí, muchos. Mi médico de familia, mi dermatólogo del seguro, el urólogo... Ya no sé qué hacer. Me han realizado cultivos, siendo negativo para hongos y mostrando escasas colonias de Escherichia coli. Me he tratado con cremas de corticoides, otras para hongos, con pomadas de antibióticos... También con cremas que llevan un poco de todo... Incluso he tomado pastillas de azitromicina y deflazacort. Cada vez peor. Aquí lo tengo apuntado. Esta última semana, he empezado a tomar Lexatin ${ }^{\circledR}$ (bromazepam) y parece que me ha calmado algo, por lo menos, por el día. Por la noche, es cuando peor estoy. No puedo dormir. Una vez tuve que llamar a emergencias, porque creí que me ahogaba, y me dijeron que era una crisis de ansiedad.

La esposa quiere intervenir. 
—Está muy angustiado - dice- - y eso no puede irle bien para su hipertensión y su colesterol alto.

En la exploración, se apreciaba en la cara anterior del escroto intenso eritema (fig. 1). La cara posterior del escroto, las ingles, el periné y la zona perianal no presentaban lesiones de ningún tipo. Con el dermatoscopio, se objetivaban abundantes telangiectasias.

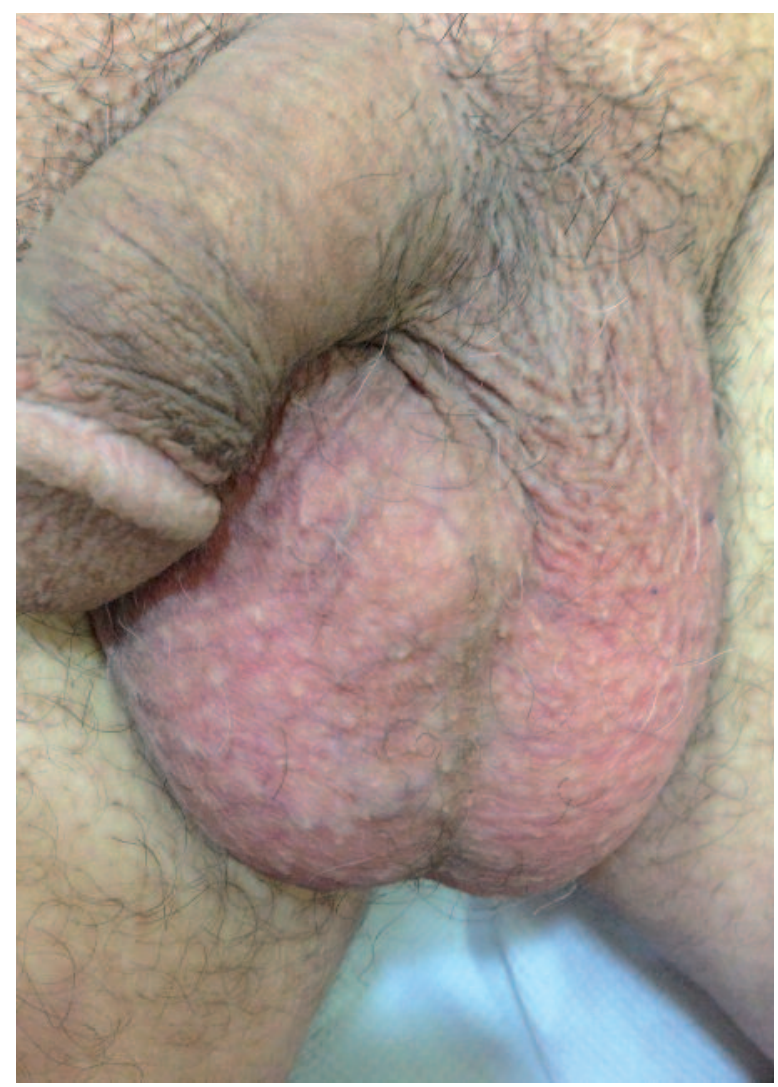

Figura 1. Síndrome del escroto rojo. Eritema y escasas telangiectasias en la cara anterior del escroto.

$\mathrm{Al}$ no ver ninguna lesión que sugiriese una enfermedad cutánea de etiología demostrable, le pregunté por su estado anímico y posible estrés previo o simultáneo a la instauración de los síntomas. Me confesó que había muerto su padre hacía poco, y que los últimos meses lo tuvo en su casa cuidándolo. Entre otras dolencias, tenía enfermedad de
Alzheimer, y ver en qué había quedado le destrozaba anímicamente.

Convencida del diagnóstico de síndrome del escroto rojo, le expliqué al paciente la naturaleza psíquica de su sufrimiento, aceptando esa posibilidad sin discusión.

El tratamiento se basó en una higiene sencilla, con jabones muy suaves, agua templada y secado sin frotar (a pequeños toques). Una crema barrera a continuación, y ropa interior de algodón y que no fuese ajustada. Como había iniciado tratamiento con bromazepam, recomendé continuar con este, aumentando la dosis hasta $6 \mathrm{mg}$. Le advertí que los glucocorticoides tópicos están contraindicados y que, si no mejoraba suficiente, le enviaría al psiquiatra. Al mes de tratamiento, había mejorado suficientemente como para poder hacer vida casi normal. En la actualidad, continúan todavía las revisiones, pero la evolución está siendo favorable.

El síndrome del escroto rojo, también llamado sindrome escrotal dependiente de corticosteroides, sindrome del escroto adicto, sindrome de enrojecimiento genital (hombres y mujeres) y síndrome pene-escroto rojo, es un cuadro clínico caracterizado por enrojecimiento persistente de la mitad anterior del escroto, con mayor o menor proporción de telangiectasias, que, ocasionalmente, puede alcanzar la base del pene y que se acompaña de picor, escozor o hiperalgesia persistente, de forma crónica y con difícil tratamiento ${ }^{1-3}$.

Suele incidir en varones mayores de 50 años. En numerosos casos, se oculta un estado depresivo en su historial.

En la exploración, se aprecia eritema y telangiectasias en la cara anterior del escroto, que pueden alcanzar la base del pene o zonas limítrofes (fig. 2). La anatomía patológica, que, habitualmente, no es necesaria, muestra en forma variable capilares dilatados y un escaso infiltrado inflamatorio inespecífico ${ }^{3}$.

La etiología es desconocida. Algunos autores ${ }^{3}$ interpretan que el origen está en el uso de glucocorticoides tópicos, que, indudablemente, influ- 


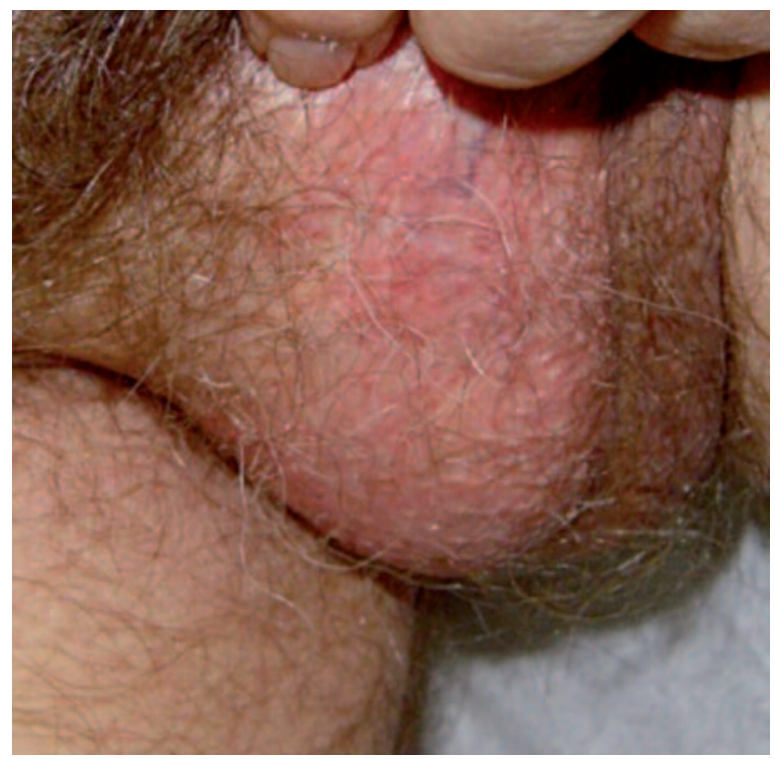

Figura 2. Síndrome del escroto rojo. No se objetivan lesiones de otra índole, salvo el eritema y las telangiectasias. Sin embargo, las molestias subjetivas pueden ser intensísimas.

yen en la permanencia del cuadro, pero que no se pueden considerar el origen, ya que el paciente tiene los síntomas antes que el eritema - escozor, picor-, motivo por el que se aplica el glucocorticoide. Los corticoides tópicos son un factor agravante del proceso, pero no la causa, ya que el paciente comienza a utilizarlos porque tiene síntomas previos de escozor y otras alteraciones subjetivas.

Sin embargo, hay otros autores que piensan que es un trastorno de la sensibilidad cutánea de origen primariamente psiquiátrico ${ }^{1,2}$, tal como ocurre con la vulvodinia, la anodinia, el síndrome de la boca urente y similares.
El diagnóstico diferencial obliga a descartar otras alteraciones con clínica similar tales como la urticaria de contacto, la dermatitis irritativa, la dermatitis alérgica de contacto, la dermatitis por corticoides, la tiña, la candidiasis, la hipocinquemia, el eritema necrolítico migratorio (glucagonoma), la psoriasis, etc., que, en la mayoría de los casos, no precisará más medios que una adecuada historia clínica.

El tratamiento requiere normas higiénicas y cuidados tópicos de hidratación sencillos. Hay que retirar los glucocorticoides tópicos, que están contraindicados, pudiendo requerir un paso previo con tacrolimús tópico y doxiciclina oral durante la disminución de estos ${ }^{4,5}$. A menudo, la explicación del proceso y el uso de ansiolíticos puede ser suficiente ${ }^{1}$. La pregabalina, útil en el dolor neuropático, también se muestra efectiva en algunos $\operatorname{casos}^{6}$. La amitriptilina es beneficiosa, sobre todo, en los pacientes con mayor componente psiquiátrico ${ }^{3}$.

\section{BIBLIOGRAFÍA}

1. Guerra-Tapia A. Manual y atlas de las enfermedades de los genitales del varón. Barcelona: Editorial Glosa, S.L.; 2008. p. 291-2.

2. Fisher BK. The red scrotum syndrome. Cutis. 1997;60(3):13941.

3. Narang T, Kumaran MS, Dogra S, Saikia UN, Kumar B. Red scrotum syndrome: idiopathic neurovascular phenomenon or steroid addiction? Sex Health. 2013;10(5):452-5.

4. Byun JW, Hong WK, Han SH, Song HJ, Lee HS, Choi GS, et al. Red scrotum syndrome: successful treatment with oral doxycycline. Int J Dermatol. 2012;51(3):362-3.

5. Wollina U. Red scrotum syndrome. J Dermatol Case Rep. 2011;5(3):38-41.

6. Miller J, Leicht S. Pregabalin in the treatment of red scrotum syndrome: a report of two cases. Dermatol Ther. 2016;29(4): 244-8. 